\title{
Multiple pulmonary rheumatoid nodules
}

\section{Gokhan Sargin, Taskin Senturk}

Department of Rheumatology, Medical Faculty, Adnan Menderes University, Aydin, Turkey

\begin{abstract}
We present a case of 45-year-old female patient with the diagnosis of seropositive rheumatoid arthritis, who was admitted to our rheumatology department with exacerbation of the disease. The patient's disease activity score (DAS 28) was 6.9. Physical examination revealed changes in the lung auscultation as a rough breathing sound at the middle and lower lobe of the right lung. Chest X-ray revealed multiple nodular densities in both lungs. Lung biopsy was performed for the diagnosis and revealed necrotizing granulomas with central fibrinoid necrosis surrounded by epithelioid cells. Such a histopathological picture is typical for rheumatoid nodules. Finally the patient was treated with rituximab, with significant improvement.
\end{abstract}

Key words: rheumatoid arthritis, rheumatoid nodule, pulmonary changes.

\section{Introduction}

Rheumatoid arthritis (RA) is an autoimmune, inflammatory and connective tissue disease, characterized by arthritis, and also may lead to organ failure. In the course of RA there can occur damage to internal organs such as the heart, lungs, and kidneys, and also the neurologic system may be affected. The prevalence of extra-articular involvement has been reported to be between $17.8 \%$ and $40.9 \%$. It may occur at any age, and equally in male and female patients [1]. However, there has been reported increased frequency for rheumatoid vasculitis, and nodules in male patients [2]. Rheumatoid nodules are seldom the cause of the symptoms of pulmonary involvement [3].

The purpose of this case report is to draw attention to the clinical and radiological findings of pulmonary rheumatoid nodules, and its presentation in patients without any typical symptoms of the respiratory system.

\section{Case report}

A 45-year-old female patient with a diagnosis of RA was admitted to our clinic, because of exacerbation of arthritis. She had a medical history of using methotrexate $10 \mathrm{mg} /$ week and acemetacin $60 \mathrm{mg} /$ day, irregularly.
On physical examination, there was a rough breathing sound at the middle and lower lobe of the right lung. The patient's Disease Activity Score (DAS 28) was 6.9, tuberculin skin test: $14 \mathrm{~mm}$. Laboratory tests showed: rheu-

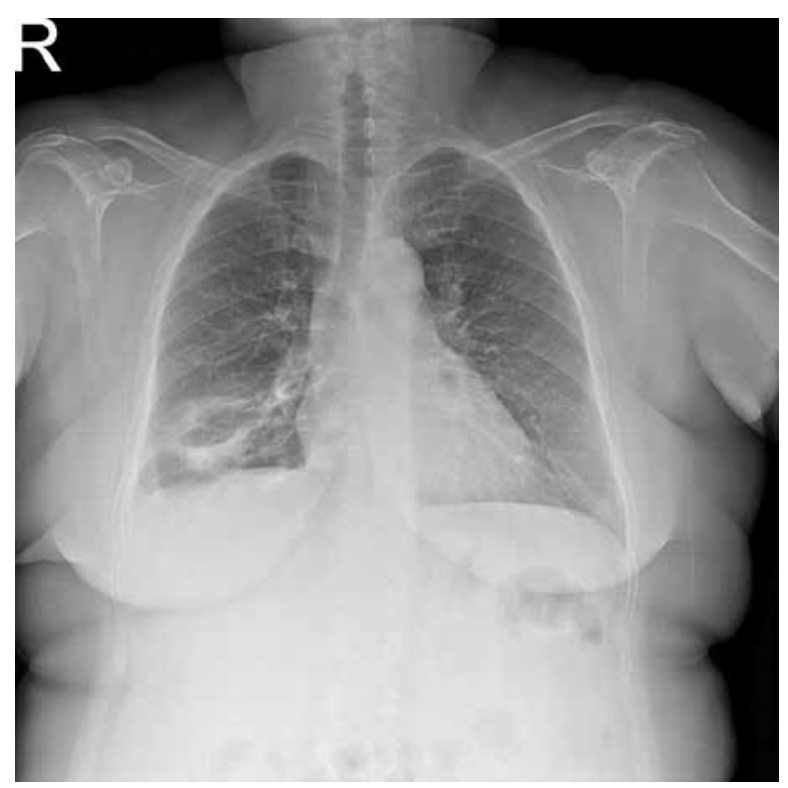

Fig. 1. Increased irregular nodular density in the lower and mid right zone.

Address for correspondence:

Gokhan Sargin, Department of Rheumatology, Medical Faculty, Adnan Menderes University, Aydin, Turkey, phone +90-506-8655990, fax +90-256-6121825, e-mail: gokhan_sargin@hotmail.com

Submitted: 01.08.2015; Accepted: 22.09.2015 

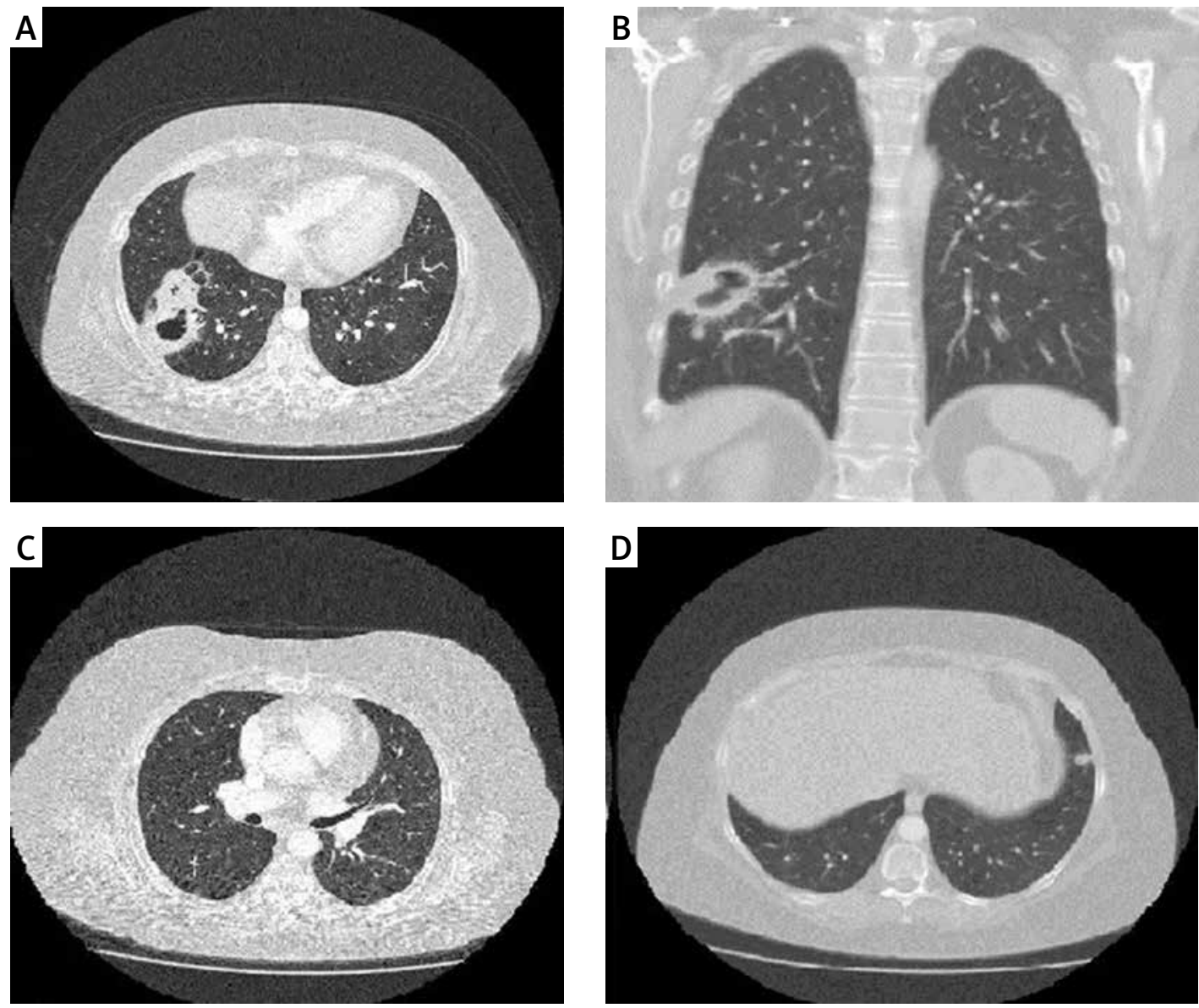

Fig. 2. Radiographic appearance of rheumatoid nodules in different areas of lung.

matoid factor (RF): $356.4 \mathrm{U} / \mathrm{ml}$, anti-cyclic citrullinated peptide (anti-CCP) > $200 \mathrm{U} / \mathrm{ml}$, and anti-nuclear antibody (ANA) was negative. Chest $\mathrm{X}$-ray showed irregular nodular density in the lower and mid right zone (Fig. 1). The sputum smear was negative for bacterial, viral, parasitic and mycobacterial infections.

Computed tomography (CT) of the chest revealed an irregular cavitated nodule $(7.5 \times 6 \times 4 \mathrm{~cm}$ in maximal diameter) in the anterobasal segment of the right lower lung (Fig. 2A), a nodule with a diameter of $7 \mathrm{~mm}$ in the posterobasal segment (Fig. 2B), a nodule with a diameter of $11 \mathrm{~mm}$ in the medial segment of the middle lobe (Fig. 2C), and an irregular nodule with a diameter of $1 \mathrm{~cm}$ in the anterior basal segment of the left lower lobe (Fig. 2D). The biopsy of the nodule revealed in histopathology necrotizing granulomas with central fibrinoid necrosis surrounded by epithelioid cells. Such a histopathological picture is typical for rheumatoid nodules. Also, bacteriological, fungal, parasitic and mycobacterial examinations were negative in the biopsy samples. The patient was started on treatment with rituximab (1000 $\mathrm{mg}$, intravenous infusion, separated by 2 weeks), with significant improvement, and the patient is still under observation in our clinic.

\section{Discussion}

It is known that RA is not only a joint disease; extra-articular findings are also important as a cause of morbidity and mortality. The life expectancy was lower in patients with RA than the general population [4]. Higher comorbidity and mortality were determined in patients with severe extra-articular involvement compared with those without such involvement [5]. Smoking, early loss of joint function, presence of ANA antibodies and RF positivity are considered as significant predictors for severe extra-articular involvement. Cardiovascular disease is responsible for a significant proportion of early mortality, but pulmonary complications associated with RA are the second most common cause of mortality and are responsible for $10-20 \%$ of all mortality [6]. Pleura, upper and lower respiratory tract, lung parenchyma, and vessels are affected in the course of RA. Infection or drug-related pneumonitis, interstitial lung disease, 
rheumatoid pneumoconiosis, and rheumatoid nodules are associated with lung parenchymal disease that can be detected in patients with RA.

Rheumatoid nodules occur in about one third of patients with seropositive disease, smokers, often in men, and generally subcutaneous form on the extensor, pressure or recurrent irritation areas [7]. Most often they occur in the subcutaneous tissue, in periarticular areas exposed to pressure. Also they may occur in other areas such as the larynx, heart valves and the lungs. However, pulmonary rheumatoid nodules are quite rare. Our female patient had a medical history of using cigarettes, as well as high positive RF and presence of anti-CCP.

Single or multiple pulmonary nodules with different sizes rarely lead to respiratory symptoms. These nodules generally do not cause any clinical symptoms such as obvious features of shortness of breath dyspnea [8, 9]. Rheumatoid nodules belong to Th1-mediated granulomas. There is central fibrinoid necrosis, epithelioid cells around and an outer zone with lymphocytes, plasma cells or fibroblasts, histologically [10]. The central zone may become a cyst, or a cavity due to the resolution of necrosis as in the present case. While pulmonary rheumatoid nodules are observed at a rate of $0.4 \%$ radiologically, this rate reaches up to $32 \%$ with biopsy in patients with RA [8]. Drugs such as methotrexate, leflunomide or anti-tumor necrosis factor (anti-TNF) agents can cause the appearance of rheumatoid nodules. Regression has been reported following treatment with tocilizumab and rituximab [11, 12]. The main problem is differential diagnosis rather than treatment. Rituximab was administered as treatment for our patient, and the patient is still on follow-up in our clinic with stable disease. Nodules observed in the lungs are considered as pulmonary rheumatoid nodules with a careful clinical and radiographic approach. However, imaging methods alone are not sufficient for definitive diagnosis. Therefore, suspicious lesions should be identified by histopathology, and other possible causes and malignancies should be excluded.

\section{Summary}

In conclusion, we have described a female patient with multiple pulmonary rheumatoid nodules - interest- ing as they were found in various zones of the lungs. However, the nodules generally presented without any symptoms of the lungs, which may be important for evaluation of further prognosis.

The authors declare no conflict of interest. References

1. Turesson C, O'Fallon WM, Crowson CS, et al. Occurrence of extraarticular disease manifestations is associated with excess mortality in a community based cohort of patients with rheumatoid arthritis. J Rheumatol 2002; 29: 62-67.

2. Prete M, Racanelli V, Digiglio L, et al. Extra-articular manifestations of rheumatoid arthritis: an update. Autoimmun Rev 2011; 11: 123-131.

3. Nannini C, Ryu JH, Matteson EL. Lung disease in rheumatoid arthritis. Curr Opin Rheumatol 2008; 20: 340-346.

4. Gabriel SE, Crowson CS, Kremers HM, et al. Survival in rheumatoid arthritis: a population-based analysis of trends over 40 years. Arthritis Rheum 2003; 48: 54-58.

5. Turesson C, McClelland RL, Christianson TJ, Matteson EL. Multiple extra-articular manifestations are associated with poor survival in patients with rheumatoid arthritis. Ann Rheum Dis 2006; 65: 1533-1534.

6. Sihvonen S, Korpela M, Laippala P, et al. Death rates and causes of death in patients with rheumatoid arthritis: a population-based study. Scand J Rheumatol 2004; 33: 221-227.

7. Lioté H. Pulmonary manifestation of rheumatoid arthritis. Rev Mal Respir 2008; 25: 973-988.

8. Yousem SA, Colby TV, Carrington CB. Lung biopsy in rheumatoid arthritis. Am Rev Respir Dis 1985; 131: 770-777.

9. Fellbaum C, Domej W, Popper H. Rheumatoid arthritis with extensive lung lesions. Thorax 1989; 44: 70-71.

10. Ziff M. Rheumatoid nodule. Arthritis Rheum 1990; 33: 761767.

11. Braun MG, Wagener P. Regression of peripheral and pulmonary rheumatoid nodules under therapy with rituximab. Z Rheumatol 2013; 72: 166-171.

12. Andres M, Vela P, Romera C. Marked improvement of lung rheumatoid nodules after treatment with tocilizumab. Rheumatology (Oxford) 2012; 51: 1132-1134. 